\title{
Physician's Use of Mandatory Information Systems: An Exploratory Research in German Hospitals
}

\author{
Heiko Gewald \\ Center for Research on Service Sciences (CROSS) \\ Neu-Ulm University of Applied Sciences, Germany \\ heiko.gewald@hs-neu-ulm.de
}

\author{
Corinna Gewald \\ Center for Research on Service Sciences (CROSS) \\ Neu-Ulm University of Applied Sciences, Germany \\ corinna.gewald@hs-neu-ulm.de
}

\begin{abstract}
Physician's use of information systems remains a highly interesting area for information systems research to the recent days. Numerous studies have been conducted to investigate the enablers and inhibitors of such use. However, no study has yet provided comprehensive insights. To advance efforts in this field, this research takes a step back and investigates the issue in an exploratory research layout. 47 informants provided input accompanied by more than 40 hours of workplace shadowing in two German hospitals.

Our findings show that focusing only on physicians does not help to answer the question. The root causes for successful system deployment are a combined approach to focus not only on the user but also on the process and the system. The three factors influence each other. Our findings also underline the importance of leadership and organizational setting.
\end{abstract}

\section{Introduction}

Developed economies all over the world see the widespread deployment of information technology (IT) in healthcare (HealthIT). Although the use of IT in hospitals (HIT) seems to be the logical thing to do and it is "no matter of if, but of when" [1], anecdotal evidence and discussions with practitioners often give the impression that HIT is not delivering up to expectations: Proof that HIT provides a measurable and sustainable positive impact to the healthcare industry is still outstanding.

Numerous authors (e.g. [2, 3]) elaborate on the expected benefits from HIT. Amongst the positive effects improvements in quality of care, decreasing healthcare delivery costs and avoidance of nonnecessary procedures are usually ranking highest. However, there are also some critical voices raised (e.g. $[4,5])$ which associate serious negative outcomes like unnecessary mortalities or redundant expenditures with the use of HIT. Still, the vast majority of researchers expects positive outcomes [2] although widely accepted proof that these expected benefits are actually delivered in daily business is still outstanding [6]. Regardless the outstanding proof hospitals in developed economies invest large amounts of money in their IT systems. Actual figures are hard to get and vary depending on sources. The material available quotes that most European hospitals spent around 2.5 to $3 \%$ of their operating budget on IT services $[7,8]$. This investment is significant and not likely to decrease over the years to come [9].

Taking the expected benefits of HIT and the investments into IT into account one wonders why literally all healthcare systems around the world have difficulties to deliver to expectations [10]. This poses the question whether HIT is really able to provide the promised benefits [11]. Naturally this question has multiple influential factors and is extremely complex to answer. Driven by personal experience and anecdotal evidence we will take a step towards answering this question by assessing the role of the. Medical personnel's acceptance of HIT has been identified as important prerequisite for successful healthcare delivery $[12,13]$. Only if users use the IT as designated the anticipated benefits will materialize [14]. Or, as Abouzahra et al. put it: "the benefits of HIS can only be reached if they are used in practice." [15, p.14]

Due to their important role in hospital settings medical personnel is often considered to be the main obstacle to successful IT deployment [16, 17]. This leads to the guiding hypotheses of this study that physicians and HIT do not go well together. This line of thought is quantitatively supported by the findings of the literature analysis of Buntin, Burke, Hoaglin and Blumenthal [2]. Accordingly, the research question of this paper is: "What are the factors that affect physician's use of HIT?"

As Lowenhaupt put it: "Physicians' adoption has long been considered 'the holy grail' of clinical information systems: critically important, but elusive". [18,p.12]. Research and practice show that there are different levels of system interaction ranging "from use to effective use" [19, p.632]. This research aims to 
provide insights how the number of "effective users" could be raised. To generate understanding regarding these complex matters a research method consisting of structured interviews combined with workplace shadowing has been chosen.

Numerous papers and several literature reviews [2, $15,17,20]$ show the enormous amount of research dedicated to investigate the enablers but mainly inhibitors to hospital medical personnel HIT usage. Unfortunately, Boonstra, Versluis and Vos [17, p.16] come to the conclusion that "the literature is diffuse, and articles seldom build on earlier ones to increase the theoretical knowledge [...]". Acknowledging this argument we decided to take a step back and -instead of looking at the symptoms- aim to target the root causes of the problem. In this respect, this research needs to be classified as exploratory. Although numerous studies have already been conducted on the issue, there is still no comprehensive understanding and literally all papers constitute that further research is needed. Therefore, the chosen approach was not to perform a quantitative study but instead -informed by the available knowledge- to conduct qualitative research.

Based on the commonly cited enablers and inhibitors of physician's use of HIT a semi structured interview guideline was developed. We conducted 47 interviews combined with more than 40 hours of workplace shadowing in two hospitals in Germany. The findings were coded, sorted and compiled into a reference framework.

The findings indicate that in a mandatory-use setting the personal likes and dislikes do not really matter. What matters are the old fashioned cornerstones of the information systems discipline: user-process-system. If these three building blocks are well aligned and correspond well with the organizational context, medical personnel show much higher satisfaction with their HIT which results in more effective use.

The paper is organized as follows: After a review the literature on IT adoption and usage in hospitals the research method is explicated. We discuss our findings and derive the proposed framework. Limitations and guidance for further research are given and the paper draws a final conclusion.

\section{Literature Review}

Countless researches have been conducted over the years trying to explain physician`s (non-)adoption of HIT. In this section we provide some brief definitions and discuss three major issues regarding the relationship between physicians and HIT in hospitals:

1. Concepts of Usage - This comprises the literature on behavior of physicians towards HIT system.
2. Mandatory Use -The specific behavior in environments where the user has no choice whether she/he wants to use a system, as usage is not voluntary.

3. Enablers and Inhibitors - A collection of previously published findings why users like or dislike HIT.

In our literature review, special consideration is given to publications in the area of medical informatics. These journals nicely complement the classic IS outlets on healthcare-related topics but are often not included in IS research papers.

\subsection{Definitions}

The term HIT is often used in different meanings. For this research it is defined as the administrative IT systems used in hospitals for managing patient related information. This includes cross-functional systems like the hospital information system (general administration, billing etc.) or the electronic medical record (patient data relating to a specific case) etc. The definition excludes function-specific medical IT systems like $\mathrm{x}$ ray machines, heart catheters etc. which are used by specialists only (although the data may feed into other administrative systems). It also needs to be pointed out that the definition focuses systems within a hospital and does not include inter-organizational systems like health information exchanges or electronic health records.

\subsection{Concepts of Usage}

Adoption, Acceptance, and Intention-to-Use. Numerous studies conducted research about the interaction of users and systems in healthcare (for reviews of the literature see $[20,21,22])$. The most popular study objects are the electronic medical record (EMR) and HIT in general. Several popular IS adoption models have been utilized (TAM, TAM2, UTAUT, SCT etc.), adapted to the healthcare context and sometimes extended by specific constructs. Some researchers argue for specific circumstances of the physician's occupation (e.g. the construct "perceived threat to professional autonomy" brought forward by Walter and Lopez [12]). However, until today we are not aware of any study which is sufficiently and significantly able to really explain why physicians do not show the same adoption behavior as users in other industries.

All the researches dealing with either adoption, acceptance, or intention-to-use (see [23] for an in-depth discussion of these terms) have one thing inherently in common: they assume a degree of freedom, i.e. that the user has a choice whether to use the system, or not. For HIT in a hospital environment this is hardly the case. Due to laws, policies, and regulations, etc. the process 
to deliver care includes an enormous part of documentation [13]. If a hospital switches from a paper based to an electronic medical record the medical personnel does not have a choice whether to use the system. He or she has to use it, whether the individual likes it, or not. As such adoption is not the question, neither is acceptance or intention.

Resistance. Reflecting the arguments above, there is of course the case of resistance defined as "opposition of a user to change associated with a new IS implementation" [24, p.567]. Under these circumstances, users try several ways not to use the system may these be active, passive, overt, or covert negative behavioral responses [25]. Some studies in the field of IS resistance have been conducted [24, 25, 26, 27, 28]. Also specific attention was dedicated to hospitals [29, 30]. All these studies highlight the importance of including the user into the implementation process as they need to change their working customs which has an impact on their work [31]. However, resistance is typically a problem that arises when change happens, i.e. before or during the implementation of a new system. Although this is an important issue to deal with, the vast majority of medical personnel in hospitals works on systems which are already implemented, i.e. the case for resistance is restricted to rather specific circumstances.

Continuous Use. To study the ongoing use of an implemented system (as opposed to the first-time use) IS research established the concept of "continuous use". Unfortunately, as pointed out by Gebauer et al. [32], considerable research [e.g. 33, 34] regards continuous use to be grounded in the same theoretical approaches as used to explain initial IT adoption (i.e. TAM, UTAUT, TRA, TPB etc.). These theories focus on "intention to use" as dependent variable which is being increasingly questioned as the link between behavioral intention and actual usage is not as strong as often expected [35] especially, if the items are self-reported [36].

Due to the focus of "intention" the aforementioned theories imply voluntary use of the system under observation. Also the few studies available which focus on the specifics of the healthcare chose non-mandatory systems (e.g. [13]).

\subsection{Mandatory Use}

In the light of the above we argue that neither studies on adoption, nor on resistance, nor on continuous use help to explain the behavior of hospital medical personnel when using an existing system in a way which is compliant with the rules and regulations of healthcare. If medical personnel conducts their daily business in a hospital, use of HIT is not voluntary but mandatory. The end-user has no choice whether to use the system, or not [37]. This decision has been made by the management when they decided to acquire this system [38].

Previous research shows, that user behavior differs in settings where system use is voluntary, or mandatory [39]. When it comes to mandatory use of systems, the number of researches in IS decreases rapidly [40]. Although practice usually provides mandatory system usage in business environments for its employees [41] research on the specific user behavior towards mandated use is scarce [42].

Of course there is always a discussion whether system use can be really mandatory or if there is always a degree of voluntarism involved [38, 43]. However, it seems to be widely accepted that "even when use is required, variability in the quality and intensity of this use is likely to have a significant impact on the realization of the system benefits" [43, p.5]. This is due to the fact that even in mandatory settings the extend of system use varies by user $[19,37]$.

However, even if the user does not like the system it does not matter as she/he does not have the choice. As such the theoretical models which focus on "intention to use" as dependent variable do not apply in mandatory context. Arguably there will be a variance in use and probably an increase in workarounds etc. but the general use of the systems is not the users' choice.

Bearing that in mind the open question remains what forms the users' behavior (in this case the degree of usage) towards the system. Which factors form positive or negative attitudes?

\subsection{Enablers and Inhibitors}

A large number of researches have been devoted to identify the factors which encourage or hinder physicians use of HIT [21]. The following section list the commonly quoted enablers and inhibitors. Where deemed necessary the original description has been complemented with additional context (in brackets) to enhance clarity. Please note that $[2,17,20,21]$ are literature reviews. If these are stated as source they represent a secondary and not a primary reference.

Enablers: Electronic data exchange with other providers [44]; Trusted colleagues using the system [21, 44]; The other members of staff are also using the system [knowledge and experience available within the department] [17]; Increasing efficient collaboration within the department [sharing documents, electronic consultation etc.] [31]; Increased mobility [gaining access to information regardless of physical location] [31]; Increasing personnel effectiveness [being able to read bad handwriting, avoid losing files etc.] [21]; Increasing productivity [increase personal efficiency 
through using text blocks, etc.] [21]; Enhances decision quality [more/better data, decision support, etc.] [21].

Inhibitors: Lack of interoperability [no connectedness with other HIT systems] [11, 45]; Insufficient ease-of-use, system too complex [difficult to find information, insufficient GUI, etc.] [11, 20]; Insufficient efficiency within the system [too many clicks required, sign -on to multiple systems, etc.] [17]; Insufficient integration with other clinical processes [coding, billing, cross-departmental consultations, etc.] [11]; Professionals need to adapt their working customs [change management issue] [31, 45]; Technology does not fit to professionals' needs / work procedures [system does not support the required functionality] [13, 17, 44, 46]; Threat to physician's professional autonomy [12, 18] [12, 47, 48]; Negative impacts on physician-patient relationship [49]; Patient privacy and information security concerns [44, 46, 48, 50, 51]; Network effect [it only makes sense to use the system if all members of the department use it, otherwise the data is incomplete] [52]; Leaders are not using the system [lack of leadership support/involvement, role model] [17]; Lack of IT-infrastructure [hardware not sufficient] [45, 46]; Insufficient speed / response times [waiting for system responses] [17]; Lack of IT support / technical assistance [17, 20, 44]; Lack of integration with existing systems [non HIT-systems such as administrative backend etc.] [46]; Lack of user's IT skills [20, 46]; Lack of knowledge and training on the system [17, 46]; Lack of system reliability [system outages] [17]; System vendor is not responsive to change requests [resulting in user frustration] [17]; Patient data in the HIT may not be complete [mistrust in data completeness] [45]; HIT provides individual's data for performance review [fear of misuse of transparency generated through HIT] [31].

These listed items serve as main input for the interview guideline as described in the next section.

\section{Research Method}

As argued in the introduction, we conducted an exploratory research and therefore deployed qualitative methods. Based on the commonly cited enablers and inhibitors of physician's HIT use a semi structured interview guideline was developed. We conducted semi-structured interviews in combination with workplace shadowing in two hospitals in Germany. The findings were coded, sorted and compiled into a reference framework.

\subsection{Research Objects}

This study is concerned with the behavior hospital personnel shows towards an information system provided by the hospital. Accordingly, the following issues need to be explicated to avoid confusion:

We did not cover the hospital as an organization which may draw benefits from HIT like improved costeffectiveness or a changing doctor-patient relationship (gearing towards a team approach instead of a 1:1 relation). We excluded this as organizational behavior follows other motives than those of individuals and therefore it is not comparable.

Individual physicians in her/his own practice (e.g. general practitioners) were also excluded as these individuals follow other motives in their behavior compared to physicians within a hospital. If a physician is responsible for her/his own practice cost considerations for example play a significant role [20]. Therefore, these individuals are very concerned about the costs for licensing, implementing and maintaining the information systems. Also financial incentives (e.g. those awarded in conjunction with the HITECH act in the US or the introduction of DRG in Germany) play a significant role in their behavior towards information system [44]. However, those physicians working in a hospital usually do not pay much attention to these considerations. Therefore physicians in their own practice and small practice units have also been excluded.

Data collection took place from June to July 2015. In order to get a broad spectrum of impressions to benefit the exploratory character of this study, users from different departments using different systems have been selected. All together 47 informants $(51 \%$ female; $49 \%$ male) provided insights. Their demographics are given in table 1 below.

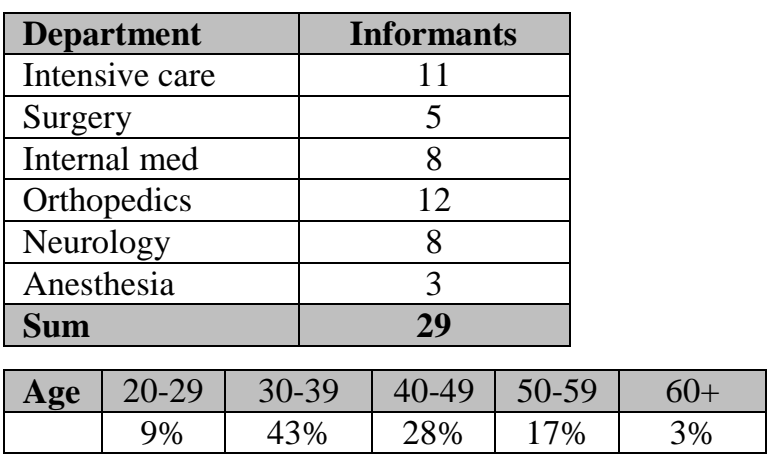

Table 1. Interview partners demographics

Data was collected at two hospitals in Germany: Hospital A is a large university medical center, ranking amongst the 10 largest hospitals in Germany. The hospital comprises of several different clinics who are departments in their own rights led by the head physician who has a joint role of medical and management responsibilities. Often, these clinics have their own IT departments. Hospital A has one unified administrative back office system (which also provides 
medical record functionality) complemented with several different HIT systems in different clinics. Several clinics use paper based medical records or a mixture between electronic and paper based records. Also, there is a variety of different electronic medical records in use and different stages of implementation. In summary, hospital A has a very complex and heterogeneous IT-landscape. Hospital B is a specialized clinic of medium size. It provides one uniform HIT system for all physicians. However, the hospital still relies to a large extend on paper based medical records.

\subsection{Semi-structured interviews}

Based on the findings of the literature review, a semi structured interview guideline was developed. This guideline consisted of three sections:

"Know your Interviewee": Demographic data of the interviewee and specification of her/his workplace and/or specific tasks/role(s)

"How do you like your HIT?" Enablers and Inhibitors identified in previous research

"How do you use your HIT": Description of the way the interviewee uses the system as part of her/his daily working routines

The interviewers made sure that all demographic information was collected for every discussion (Section 1) either directly with the informant or through other sources. Section 2 was an open discussion and the interviewer put specific focus on enablers/inhibitors listed above. As these issues were addressed as open questions, interviewees often picked there most pressing issues and talked about these for some time. Towards the last third of the interview, the interviewer engaged section 3 to gain an understanding of the way the physician uses the HIT to perform her/his daily tasks.

Due to the sensitivity of the matters the overwhelming majority of interviewees did object to having the interviews recorded or full minutes been taken by a second interviewer. As such the team needed to rely on notes taken during the conversation.

\subsection{Workplace Shadowing}

A common problem in social sciences is the disparity between self-reported behavior and the actual observable actions. To mitigate this effect, we chose to not only rely on interviews but to conduct workplace shadowing. The team spent more than 40 hours accompanying physicians on their ward rounds, during team meetings and observing their general work. Our main goal was to actually "see" how the physician interacts with the system.

\subsection{Data Analysis}

Interpretation of the data collected was done as suggested by Miles, Huberman and Saldana [53]: All notes taken during the interviews were reviewed, clarified as necessary and coded. Open coding was guided by association to either one of the known enablers/inhibitors (section 2.4), or by associating a new concept. Following open coding, axial coding was performed to ensure all important aspects have been identified. Coding was done by two researchers independently. All disputes were discussed until a unanimous agreement was reached.

Result of the coding was a table which lists the major categories and associated concepts. These were put into perspective to form a framework to structure the findings.

\section{Discussion of Findings}

Our findings underline that physicians are generally not technophobe. They value technology but not for the sake of technology itself but much more on a rationale layer in line with Lowenhaupt [18]: Technology is considered being good when it is useful to complete a task or process in a more efficient or effective way compared to a given alternative. This "alternative" is usually not a different system but a workaround (e.g. writing paper notes instead of putting the data directly into the system) or the delegation of interaction with the system (e.g. asking a team member to putting in data on behalf of the physician) (see also the findings of [4]).

So the answer to our ingoing hypothesis is not rooted in physicians generally not liking technology. We found evidence which support both: (semi-)rational and emotional arguments for the way physicians interact with the provided HIT. The result of our coding (main categories) is depicted in Figure 1 below. 


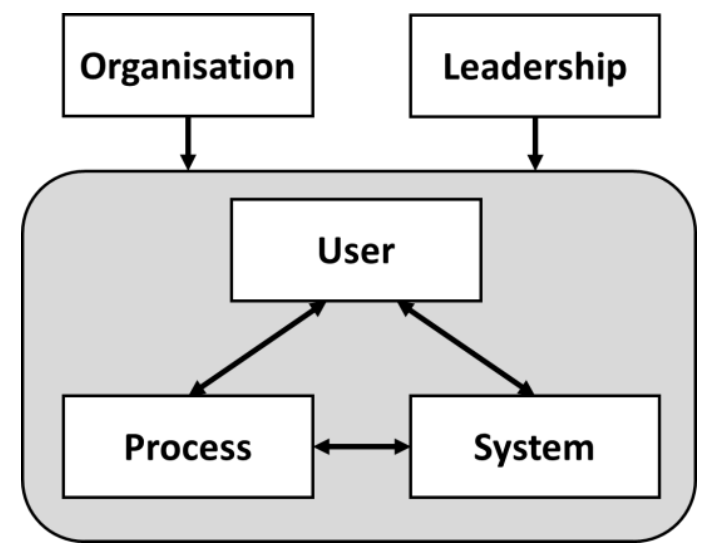

Figure 1: $\quad$ Framework of Findings

Interpretation of statements and observations indicate a clear relationship between user, process and system - all influencing each other respectively. Also leadership and organization have strong impact. The individual categories and their relationship are discussed in the following sections.

\subsection{User - Process - System}

Our sample represents all types of users: those who are happy with the HIT and those who openly dislike it. In line with the findings of Chau and $\mathrm{Hu}$ [48] we see that physicians usually show a positive attitude towards the HIT when it closely matches their established work behavior, i.e. a good fit between user, system and process. It needs to be noted that physicians' attitude is strongly influenced by the behavior of their superiors (this influence is discussed in section 4.2).

User. The category "user" comprises the findings around the person using the system. It deals predominantly with issues of knowledge and skills but also with personal efficiency and professional autonomy.

We saw that the users were happy with the HIT when they had the feeling that they could get their work done faster (i.e. more efficient and/or effective). Better exchange of / access to information, being able to read all entries [issue of bad handwriting on paper files] and decision support were named as major enablers. Although the informants had different attitudes towards IT in general, no one refused to work with the system. Some felt that their work is increasingly becoming too IT focused ("At some point in time we all will have to study computer sciences to do our job" [N04]).

The impact on the relationship between patient and physician was valued differently, depending on the specialization of the informant. Especially when a lot of physical interaction with the patient was necessary (e.g. orthopedics) the use of HIT was not perceived too helpful. On the other hand it was noted that patients perceive it positively when advanced technology is utilized ("I like working with the system. It shows patients that we are up to date" [N05]). Several informants complained about the HIT lagging behind modern hard- /software concepts like smartphones, tablets and apps. A general perception was that "My work as a doctor is not valued when the IT I am given does not meet my needs" [P19]. It needs to be noted that previous research showed that physicians have a tendency to regard IT gadgets as status symbol [54].

The effect of training was considerable. Physicians who attend training sessions on the system were more comfortable using the system and (from observation) faster and more knowledgeable (i.e. were able to use more functionality). Physicians acknowledge that training is helpful ("It was very hard to use the system in the beginning but the training helped a lot to make the most out of it" [P07]), however previous research also shows that they have a great tendency to not attend training sessions [55].

The issue of being too transparent (e.g. for performance reviews or lawsuits) as the HIT tracks and timestamps all action was also brought up by the informants. Also, anecdotal evidence from outside this study as well as previous research [31] indicates this may be a problem when assessing the role of HIT.

Process. The category "process" comprises the findings around the process of healthcare delivery as it requires interaction with the HIT (i.e. not the physical treatment but diagnosis etc.).

The findings underline that HIT can be really beneficial if it is used as designated. When information is put in timely and accurately the major tasks (like writing the doctor's letter) is very quickly done: "We continuously update our doctor's letters as part of our documentation and so in the end they are done very quickly." [P13]. However, this also requires all necessary systems to be integrated: "Writing doctor's letters is the task we like to postpone most because it takes so much time to retrieve all information needed from the system." [P04]. However, some informants mentioned information overload ("I don't want all the information automatically thrown on to me. As a doctor I want to think and make my own decisions." [P10] and others have a general mistrust in the information provided by the system ("With all that copying and pasting one cannot trust the information in the system all the time." [P14]). So system integration and data integrity seem to be a key requirement for successful working processes.

Established work habits can be a serious inhibitor to system use. We observed that physicians are rarely willing to adapt their working procedures to the system. Much more they want the system to reflect their individual (or departmental) working habits. This poses a problem to off-the-shelf software as these are typically 
limited in their range of customization. Even though it is possible to customize the software history (especially in the manufacturing industry) has shown that heavy customization leads to system incompatibilities and update problems over time. Individually developed software would be the natural response, however, due to the high costs involved in maintaining this it is generally out of the question for most hospitals.

System. The category "system" comprises the findings associated with the actual HIT and its deployment.

A major recurring critique was the graphical user interface (GUI). This was frequently regarded as either being too complex or "not made for doctors" [P05]. This links in with the findings in the process-category on the established working habits. Additionally, the physicians complained about multiple logons to different systems (as opposed to a single sign on) or the need to press too many buttons before being able to retrieve information (Observation [P02]).

Regarding the infrastructure a recurring negative factor were long response times (subjective observation during workplace shadowing) and system outages/crash. Although concerns with IT security and data privacy were frequently reported in previous research these issues were not mentioned by our informants.

Relationship of User-Process-System. These three categories appear to be tightly coupled. As we know from the concept of Task-Technology-Fit [56] a systems is best accepted when the technology provided fits the task the user needs to perform. In the case of our research we saw that physicians generally are not opposing the HIT provided. They are struggling with the GUI and (perceived) long response times. Incomplete or difficult to get-to information was another inhibitor. Some of these factors can be addressed by training and investment in IT-infrastructure. Still, the problem prevails that no off-the-shelf software is able to support all established working processes in all hospitals (not even close to it). So in order to efficiently support the physician the systems need to change (GUI, single sign on, data integration) but also the processes (adapt the clinical processes to a standard-model which can be supported by a commercial software) and the users need to do their part (e.g. attend training session).

These three factors are so closely connected to each other that there seems to be no way forward by just addressing one of them.

\subsection{Leadership}

The category "leadership" comprises the findings which relate to the medical and administrative management and the respective influence on the inner framework (user-process-system).

In a hospital context, two forms of leadership need to be segregated: medical management (leadership exerted by the medical superiors (e.g. the head physician)) and administrative management, i.e. the hospital administration.

Medical Management. In hospitals, the medical management is actually split in to two functions: the administrative and the medical management role. This is due to the fact, that the head physician carries overall responsibility for her/his department. This includes medical practices as well as organizational and financial responsibilities. This segregates the healthcare context from other industries where management roles typically only have the managerial role but usually not direct operational responsibility. In hospitals the head of the surgery department usually undertakes the most difficult procedures her/himself as opposed to car manufacturing for example the head of engineering typically does not maintain engines. This has important implications for research. Our findings clearly underline the important role the superior plays in forming attitudes and behavior towards HIT in her/his department. Whenever the head was skeptical of HIT e.g. "Technology is necessary these days but paper is faster and more efficient [P01]" this attitude was mostly seen in the overall department, and vice versa. The strong impact of medical management towards HIT derives from the double role of medical and managerial responsibility. The department head strongly influences the working procedures, has a (if not THE) leading role in HIT system selection and decides how much budget will be spent on systems development (new functionalities, integration with other systems etc.).

Administrative Management. The hospital administration traditionally has a difficult position towards the medical directors. This is mainly due to being financially responsible for the hospital but not having a medical say. This makes it difficult to assert overall leadership as there is not direct supervision. This can lead to the situation that different departments deploy different HIT for the same purpose. This does not only cost a lot of money but it makes integration and standardization much more difficult. However, interfering with the systems selection of the individual department can prove difficult if medical management argues on basis of medical procedures.

Influence of Leadership towards User-ProcessSystem. The findings show that leadership on all levels plays an important role. We saw that in units where the medical management (head physician) is a strong supporter of HIT the attitude of the physicians towards the system was much better compared to other wards. This is not surprising as the head physician carries 
ultimate responsibility for all actions within the whole department and as such strongly influences working practices.

When medical management encourages system usage the users were much more satisfied with the system. If administrative management (probably together with medical management) fosters consolidation, integration and in some instances standardization of systems the benefit for all users of the HIT increased. In hospitals with overall the same HIT the users were more satisfied with the system than in settings with diverse IT landscape.

If management has a shared vision towards HIT and is prepared to put in the effort to bring this vision into practice the overall outcome is rewarding as it directly influences the construct user-process-system.

\subsection{Organization}

The category "organization" comprises the findings around the organization of work within the hospital.

Main issue raised by the physicians was the inferior organizational integration with other departments. Due to the leadership described above no coherent system and process integration structure was found around the hospital. This result in a complex IT landscape which comprises several different HIT systems and heterogeneous working procedures: "I have to put the request for a counsel into the system, print and sign it, fax the request to the other department and yet I have to call them every time to make sure they get the information" [P22].

An additional observation was that many physicians felt the IT department too distant from the medical professions. They found it difficult to communicate and interact with IT personnel. This observation links into the recurring IS discussions on IT/Business alignment as previous work shows that hospitals with good alignment perform better than hospitals with isolated departments [57].

As such the organizational factor has great indirect impact on the user-process-system construct. When the organization is well aligned we see that also the overall performance increases.

\subsection{Summary}

In summary the interviews and workplace shadowing showed that physicians are willing to work with the systems when they help them to do their job more efficiently. The latter derives from a good coordination between user, process and system. Our general observation was the better this construct works, the better the physicians interact with their system and achieve better results.
We also saw the influence of leadership (strong and coordinated leadership enables good use of IT) and the impact organizational alignment has on system use.

As such our framework consists of an inner model (user-process-system) where all factors influence each other and an outer model (leadership and organization) which has a directed influence on the inner model.

\section{$5 \quad$ Limitations and Further Research}

This research is an exploratory qualitative study to provide deeper insights into the way physicians use the HIT systems provided by the hospital. Due to only visiting two sites and interviewing a limited number of users it lags generalizability. Also, regretfully, we were not allowed to tape or minute the conversations therefore we needed to rely on protocols taken from memory.

Future research could benefit from our findings by finding a basis for comparing different sites with different organizational etc. settings. Our findings point in some directions but more research is need to confirm.

\section{Implications}

Our findings show that different IS research strands are required to explain use of HIT by hospital physicians. We found not only a basis to argue with Task-Technology-Fit but also detected the influence of business/IT-alignment. We found evidence that the overall topic is currently not good enough understood to conduct large scale quantitative research which goes beyond descriptively naming the top enablers and inhibitors. In order to assess the specifics of HIT use in hospitals more research is necessary and we hope that our framework is able to guide some thoughts.

From a practical perspective we were able to provide some issues which are far too often overlooked when implementing HIT systems. There is a serious need for Business Process Reengineering. The same as in other industries also applies for hospitals. A (new) system does not solve a problem. Only a combined effort of system customization together with adapting working habits seems to lead to success. This requires also a serious change management effort. Additionally more focus should be put on GUI development and IT-topics which have a direct user impact (like response times and multiple logons). Certainly it will never be possible to satisfy all users but more effort in the areas mentioned can actually help to increase user satisfaction.

\section{Conclusion}


We conducted an exploratory study into the question how users in hospitals use the mandatory HIT systems the hospital provides. In this setting we were interested in the enablers and inhibitors of system use. Our findings show that not only the traditional focus areas of information systems research: user, process and system are important but also leadership and organizational setting play a crucial role in forming the behavior.

Physicians showed a generally positive attitude towards the system. The main reason that prevented effective use was insufficient support of the working procedures. This may be caused by both sides: (1) Insufficient systems integration and/or inadequate systems deployed by the hospital, as well as (2) traditional work processes which do not go along with the systems in place and users who are unwilling to change these procedures.

\section{References}

[1] Wiggins, C., Peterson, T., and Moss, C., "Ambulatory Surgery Centers' Use of Health Information Technology", Health Policy and Technology, 4(2), 2015, pp. 100-106.

[2] Buntin, M.B., Burke, M.F., Hoaglin, M.C., and Blumenthal, D., "The Benefits of Health Information Technology: A Review of the Recent Literature Shows Predominantly Positive Results", Health Affairs, 30(3), 2011, pp. 464-471.

[3] Denis, P., "Integrated Care Needs Integrated Information Management and Technology", Healthcare Quarterly, 13(Sp), 2009, pp. 24-29.

[4] Ash, J.S., Berg, M., and Coiera, E., "Some Unintended Consequences of Information Technology in Health Care: The Nature of Patient Care Information System-Related Errors", Journal of the American Medical Informatics Association, 11(2), 2004, pp. 104-112.

[5] Koppel, R., "Great Promises of Healthcare Information Technology Deliver Less", in: Healthcare Information Management Systems (Weaver, C.A., Ball, M.J., Kim, G.R., and Kiel, J.M., 'eds.'), Springer International Publishing, 2016, pp. 101-125.

[6] Shekelle, P., Morton, S.C., and Keeler, E.B., "Costs and Benefits of Health Information Technology", in: Evidence Reports/Technology Assessments, No. 132 (Agency for Healthcare Research and Quality (Us), 'ed.' 2006

[7] European Commission, "Anteil Der It-Aufwendungen Am Gesamtbudget Europäischer Krankenhäuser Im Jahr 2013", 2013

[8] Buddrus, U., "It Benchmarking Im Krankenhaus Mit Himss' Europäischen Emr Adoption Model", Austrian eHealth Summit, Wien, 23. Mai 2013, 2013

[9] Idc, "Idc Health Insights Western European Healthcare Providers It Spending Forecast 2014-2018", 2015

[10] Davino, J.M., "Complexities of Delivering Health Care", The Journal of Global Health Care Systems, 1(4), 2011, pp. 1-9.

[11] Kellermann, A.L., and Jones, S.S., "What It Will Take to Achieve the as-yet-Unfulfilled Promises of Health Information Technology?", Health Affairs, 32(1), 2013, pp. 63-68.
[12] Walter, Z., and Lopez, M.S., "Physician Acceptance of Information Technologies: Role of Perceived Threat to Professional Autonomy", Decision Support Systems, 46(1), 2008, pp. 206-215.

[13] Tulu, B., Burkhard, R., and Horan, T.A., "Information Systems and Health Care Xiv: Continuing Use of Medical Information Systems by Medical Professionals: Empirical Evaluation of a Work System Model", Communications of the Association for Information Systems, 18(1), 2006, p 31.

[14] Engelbert, R., and Graeml, A., "Beyond It Acceptance", Proceedings of the 21st Americas Conference on Information Systems, 2015

[15] Abouzahra, M., Guenter, D., and Tan, J., "Integrating Information Systems and Healthcare Research to Understand Physicians' Use of Health Information Systems: A Literature Review", International Conference on Information Systems, 2015

[16] Paré, G., Sicotte, C., and Jacques, H., "The Effects of Creating Psychological Ownership on Physicians' Acceptance of Clinical Information Systems", Journal of the American Medical Informatics Association, 13(2), 2006, pp. 197-205.

[17] Boonstra, A., Versluis, A., and Vos, J.F., "Implementing Electronic Health Records in Hospitals: A Systematic Literature Review", BMC health services research, 14(370), 2014, pp. 1-24.

[18] Lowenhaupt, M., "Removing Barriers to Technology", Physician executive, 30(2), 2004, pp. 12-14.

[19] Burton-Jones, A., and Grange, C., "From Use to Effective Use: A Representation Theory Perspective", Information Systems Research, 24(3), 2012, pp. 632-658.

[20] Boonstra, A., and Broekhuis, M., "Barriers to the Acceptance of Electronic Medical Records by Physicians from Systematic Review to Taxonomy and Interventions", BMC health services research, 10(1), 2010, p 231.

[21] Holden, R.J., and Karsh, B.-T., "The Technology Acceptance Model: Its Past and Its Future in Health Care", Journal of Biomedical Informatics, 43(1), 2010, pp. 159-172.

[22] Shaikh, A.A., and Karjaluoto, H., "Making the Most of Information Technology and Systems Usage: A Literature Review, Framework and Future Research Agenda", Computers in Human Behavior, 49(2015, pp. 541-566.

[23] Venkatesh, V., and Davis, F.D., "A Theoretical Extension of the Technology Acceptance Model: Four Longitudinal Field Studies", Management science, 46(2), 2000, pp. 186-204.

[24] Kim, H.-W., and Kankanhalli, A., "Investigating User Resistance to Information Systems Implementation: A Status Quo Bias Perspective", MIS quarterly, 33(3), 2009, pp. 567-582.

[25] Laumer, S., and Eckhardt, A., "Why Do People Reject Technologies: A Review of User Resistance Theories", in: Information Systems Theory, Springer, 2012, pp. 63-86.

[26] Laumer, S., Maier, C., Eckhardt, A., and Weitzel, T., "User Personality and Resistance to Mandatory Information Systems in Organizations: A Theoretical Model and Empirical Test of Dispositional Resistance to Change", Journal of Information Technology, 2015.

[27] Hirschheim, R., and Newman, M., "Information Systems and User Resistance: Theory and Practice", The Computer Journal, 31(5), 1988, pp. 398-408. 
[28] Lapointe, L., and Rivard, S., "A Multilevel Model of Resistance to Information Technology Implementation", MIS quarterly, 29(3), 2005, pp. 461-491.

[29] Doolin, B., "Power and Resistance in the Implementation of a Medical Management Information System", Information Systems Journal, 14(4), 2004, pp. 343-362.

[30] Bhattacherjee, A., and Hikmet, N., "Physicians' Resistance toward Healthcare Information Technology: A Theoretical Model and Empirical Test", European Journal of Information Systems, 16(6), 2007, pp. 725-737.

[31] Liu, C.-F., and Cheng, T.-J., "Exploring Critical Factors Influencing Physicians' Acceptance of Mobile Electronic Medical Records Based on the Dual-Factor Model: A Validation in Taiwan", BMC medical informatics and decision making, 15(1), 2015, p 125.

[32] Gebauer, L., Söllner, M., and Leimeister, J.M., "Towards Understanding the Formation of Continuous It Use", Proceedings of the 34th International Conference on Information Systems, 2013

[33] Bhattacherjee, A., "Understanding Information Systems Continuance: An Expectation-Confirmation Model", MIS quarterly, 25(3), 2001, pp. 351-370.

[34] Karahanna, E., Straub, D.W., and Chervany, N.L., "Information Technology Adoption across Time: A Cross-Sectional Comparison of Pre-Adoption and Post-Adoption Beliefs", MIS quarterly, 1999, pp. 183-213.

[35] Limayem, M., Hirt, S.G., and Cheung, C.M., "How Habit Limits the Predictive Power of Intention: The Case of Information Systems Continuance", MIS quarterly, 31(4), 2007, pp. 705737.

[36] Wu, J., and Du, H., "Toward a Better Understanding of Behavioral Intention and System Usage Constructs", European Journal of Information Systems, 21(6), 2012, pp. 680-698.

[37] Melone, N.P., "A Theoretical Assessment of the UserSatisfaction Construct in Information Systems Research", Management science, 36(1), 1990, pp. 76-91.

[38] Vehring, N., Riemer, K., and Stefan, K., "“Don't Pressure Me!" Exploring the Anatomy of Voluntariness in the Organizational Adoption of Network Technologies", Proceedings of the 32nd International Conference on Information Systems, 2011

[39] Gallivan, M.J., "Organizational Adoption and Assimilation of Complex Technological Innovations: Development and Application of a New Framework", The DATA BASE for Advances in Information Systems, 32(3), 2001, pp. 51-85.

[40] Chan, F.K., Thong, J.Y., Venkatesh, V., Brown, S.A., Hu, P.J., and Tam, K.Y., "Modeling Citizen Satisfaction with Mandatory Adoption of an E-Government Technology", Journal of the Association for Information Systems, 11(10), 2010, pp. 519549 .

[41] Brown, S.A., Massey, A.P., Montoya-Weiss, M.M., and Burkman, J.R., "Do I Really Have To? User Acceptance of Mandated Technology", European Journal of Information Systems, 11(4), 2002, pp. 283-295.

[42] Laumer, S., Maier, C., Eckhardt, A., and Weitzel, T., "Why Are They Grumbling About My New System? Theoretical Foundation and Empirical Evidence of Employee Grumbling as a User Resistance Behavior", Proceedings of the 35th International Conference on Information Systems, 2014
[43] Delone, W.H., and Mclean, E.R., "Information Systems Success Revisited", Proceedings of the 35th Hawaiian International Conference on System Sciences, 2002, pp. 2966-2976.

[44] Heisy-Grove, D., and Patel, V., "Physician Motivations for Adoption of Electronic Health Records" (The Office of the National Coordinator for Health Information Technology, 'ed.' 2014

[45] Lærum, H., Ellingsen, G., and Faxvaag, A., "Doctors' Use of Electronic Medical Records Systems in Hospitals: Cross Sectional Survey", Bmj, 323(7325), 2001, pp. 1344-1348.

[46] Villalba-Mora, E., Casas, I., Lupiañez-Villanueva, F., and Maghiros, I., "Adoption of Health Information Technologies by Physicians for Clinical Practice: The Andalusian Case", International Journal of Medical Informatics, 84(7), 2015, pp. 477-485.

[47] Weeger, A., and Gewald, H., "Acceptance and Use of Electronic Medical Records: An Exploratory Study of Hospital Physicians' Salient Beliefs About Hit Systems", Health Systems, 4(1), 2015, pp. 64-81.

[48] Chau, P.Y.K., and Hu, P.J.-H., "Investigating Healthcare Professionals' Decisions to Accept Telemedicine Technology: An Empirical Test of Competing Theories", Information \& Management, 39(4), 2002, pp. 297-311.

[49] Shachak, A., and Reis, S., "The Impact of Electronic Medical Records on Patient-Doctor Communication During Consultation: A Narrative Literature Review", Journal of evaluation in clinical practice, 15(4), 2009, pp. 641-649.

[50] Thomas, T., "A Computer Security Expert's Perspective on Electronic Medical Records", Journal of Controversial Medical Claims, 15(2), 2008, pp. 19-20.

[51] Gold, M.R., Mclaughlin, C.G., Devers, K.J., Berenson, R.A., and Bovbjerg, R.R., "Obtaining Providers' 'Buy-In'and Establishing Effective Means of Information Exchange Will Be Critical to Hitech's Success", Health Affairs, 31(3), 2012, pp. 514-526.

[52] Kralewski, J.E., Dowd, B.E., Cole-Adeniyi, T., Gans, D., Malakar, L., and Elson, B., "Factors Influencing Physician Use of Clinical Electronic Information Technologies after Adoption by Their Medical Group Practices", Health care management review, 33(4), 2008, pp. 361-367.

[53] Miles, M.B., Huberman, A.M., and Saldana, J., Qualitative Data Analysis: A Methods Sourcebook, Sage, 3rd edn, 2013.

[54] Weber, M., Gewald, C., Weeger, A., and Haase, U., "The Effect of 'Device' in Task-Technology Fit a Study of German Hospitals", Proceedings of the Forty-NinthHawaii International Conference on Systems Sciences, Hawaii, 2016

[55] Weber, M., and Gewald, H., "'I Don't Have Time for That" Examining the Impact of Training on Physician's Task Performance", Proceedings of the 5th Workshop on Health IT and Economics, 2014

[56] Goodhue, D.L., and Thompson, R.L., "Task-Technology Fit and Individual Performance", MIS quarterly, 19(2), 1995, pp. 213236.

[57] Weeger, A., "What Qualifies Project-Related Artefacts to Bridge Boundaries in Is Implementation Projects - an Activity Theoretical Perspective", 50th Hawaiian International Conference on System Sciences, 2017 